\title{
“This is My Community": Reproducing and Resisting Boundaries of Exclusion in Contested Public Spaces
}

\author{
Erin E. Toolis ${ }^{1}$ (D) Phillip L. Hammack ${ }^{1}$
}

Published online: 24 September 2015

(c) Society for Community Research and Action 2015

\begin{abstract}
The way that public space is structured has significant implications for identity, social interaction, and participation in society. For those experiencing homelessness, with no or limited private space, survival hinges on the accessibility and livability of public space. However, the increasing privatization of public space in the United States has contributed to the implementation of antihomeless ordinances in cities, restricting sitting, standing, panhandling, and sleeping in public. This study analyzes data from interviews with housed and unhoused community members, text from a local policy document, and ethnographic observations to explore how boundaries between "insiders" and "outsiders" are drawn in public space and mediated through individual discourse. Our findings suggest that boundaries of exclusion are constructed through dominant narratives that portray the unhoused as a threat to safety and economic vitality, thus justifying the need for regulation and punishment through the criminalization of homelessness. Yet, informants also demonstrate resistance to this narrative by discussing how criminalization of homelessness perpetuates dehumanization, violence, and economic inequality. Policy implications for the regulation of public space are discussed.
\end{abstract}

Keywords Homelessness - Public space - Narrative . Policy $\cdot$ Discourse $\cdot$ Moral exclusion

Erin E. Toolis

eetoolis@ucsc.edu

1 Department of Psychology, Psychology Faculty Services, University of California, Santa Cruz (UC Santa Cruz), 1156 High Street, Santa Cruz, CA 95064, USA

\section{Introduction}

I see downtown as a battleground. I see downtown as ground zero.

-Maria (40, female, white, housed)

I always have to talk to cops, and it's like, even when I'm just going to the bathroom... after a while, I'm just like, this is a war against people like me...

-Leonard (34, male, white, unhoused)

The question of who "belongs" in public space is one that is hotly contested and has profound implications for identity, social interaction, and participation in society. For individuals experiencing homelessness, with no or limited private space, survival hinges on the accessibility of public space (Snow and Mulcahy 2001). However, public space is governed by material and symbolic boundaries separating "insiders" from "outsiders," which are negotiated through discourse and institutionalized through public policies (Dixon and Durrheim 2000). The reproduction and resistance of these boundaries have dramatic consequences for determining who is considered a legitimate community member, who is considered deserving of rights and protection, and whose stories are heard (Rappaport 2000).

This study utilizes a narrative approach to investigate how downtown public space is discursively constructed by different community stakeholders and what impact this conversation has on the framing of homelessness as a social problem. We investigated the following questions: How do policies regulating public space discursively construct and frame boundaries of inclusion and exclusion? How do housed and unhoused community members engage with these boundaries through discourse? To address the first question, we used ethnographic methods that included analysis of policy documents related to public space and its 
regulation. To address the second question, we conducted interviews with housed and unhoused members of a community to interrogate the relationship between the way space is discursively constructed in more formal and collective spaces and the way individuals appropriate that discourse. This approach is anchored in theoretical notions of narrative engagement, which seeks to link stories that circulate in a social context, materialized in policies and cultural artifacts, with personal narratives (see Hammack 2008, 2011).

\section{Economic Inequality and the Privatization of Public Space}

There are two visions of America a half century from now. One is of a society more divided between the haves and the have-nots, a country in which the rich live in gated communities, send their children to expensive schools, and have access to first-rate medical care. Meanwhile, the rest live in a world marked by insecurity... Economists have given it a name, a dual economy, two societies living side by side, but hardly knowing each other, hardly imagining what life is like for the other. Whether we will fall to the depths of some countries, where the gates grow higher and the societies split farther and farther apart, I do not know. It is, however, the nightmare towards which we are slowly marching. (Stiglitz 2012, pp. 361-362).

Due to rising economic inequality in the United States (US), the rich and poor occupy increasingly different worlds (Reich 2010; Stiglitz 2012). Economic segregation in the US is at its highest level in decades (Reich 2010; Stiglitz 2012). Shifts in the labor market have contributed to the polarization of job opportunities, marked by rising wages for high-paying jobs and decreasing wages for lowpaying jobs (Autor 2011). One alarming indicator of this growing crisis is the gap between wages and housing costs. Whereas the housing market has expanded for high-income renters, low-cost and subsidized housing options have steadily diminished [National Low Income Housing Coalition (NLIHC) 2014]. In 2014, there was not a single state in the US in which a full-time minimum wage worker could afford a one or two bedroom rental at fair market rent without spending more than $30 \%$ of their monthly income (NLIHC 2014). Lack of access to adequate wages and affordable housing place poor and low-income individuals and families at serious risk of eviction and foreclosure (Shinn et al. 2001). On any given night, approximately 610,000 Americans experience homelessness with over one-third unsheltered (U.S. Department of Housing and Urban Development 2013).
Economic segregation is further compounded by the privatization of public space. Although residential areas are often spatially divided along lines of race and class, urban streets, and especially downtown areas, serve as a place of intersection where individuals from diverse backgrounds may encounter one another (Susser 1996; White 1993). However, as cities privatize public spaces in the hopes of attracting revenue from consumers and investors, downtown areas are increasingly converted into spaces of entertainment and commerce, marked by the pervasive presence of shopping malls, advertisements, and surveillance (Banerjee 2001; Ferrell 1997). Initiatives for "revitalization" and "urban renewal" often commodify public space, catering to the needs and interests of middle class and elite users, while devaluing and displacing low income and poor community members. Spatial segregation "reflects the desire and ability of the middle class to distance itself from the poor" and contributes to the designation of the unhoused as "other," seen as unwelcome intruders and vagrants (Amster 2003; Lott 2002, p. 105). Thus, research suggests that America's "dual economy" is creating dual habitats-bifurcated into central and marginal spaces: spaces of consumption and spaces of refuse (Wright 1997). The boundary between these spaces is institutionalized through policies that criminalize homelessness in public places (Wright 1997).

\section{Public Space and the Criminalization of Homelessness}

Examples of anti-homeless legislation are pervasive across the US. Research by the National Law Center on Homelessness and Poverty (NLCHP) with 234 US cities found that $53 \%$ prohibited sitting or lying in particular public places, $76 \%$ prohibited panhandling, $65 \%$ prohibited loitering, and $43 \%$ prohibited sleeping in vehicles (2014). Removing public benches, closing parks after dark, the removal of publicly stored belongings, and sweeps of "illegal" campsites are also common (Gaetz 2004; Snow and Mulcahy 2001). At the same time, most cities with these restrictions do not provide sufficient shelter beds, public bathrooms, or storage options for those experiencing homelessness (NLCHP 2014). These ordinances lead to higher rates of arrest and incarceration for unhoused individuals, with research suggesting that about half of unhoused individuals have spent five or more days in a county jail in their lifetime (Substance Abuse and Mental Health Services Administration 2011). However, the nature of these "crimes" tend to be predominantly nonviolent, relating to "quality of life" or "public nuisance" offenses (Ammann 2000; Snow et al. 1989).

These policies have very real consequences for those without shelter. Based on a survey conducted by the 
Western Regional Advocacy Project (2014) with 336 homeless individuals in the US, the majority (between 66 and $81 \%$ ) reported being harassed for sleeping, sitting or lying on the sidewalk, and loitering, and about half had received citations for these survival-related activities. Increasing surveillance in downtown areas and locating services in less accessible, less safe areas pushes unhoused people out of the public eye, increasing social isolation as well as the risk of victimization (Wright 1997). The National Coalition for the Homeless (NCH 2014) found that prejudice against unhoused individuals often contributes to violence and hate crimes, including beatings, rape, and murder. In 2013, 109 attacks classified as hate crimes were documented against homeless individuals by housed individuals, resulting in eighteen deaths $(\mathrm{NCH}$ 2014). Exposed to the elements, experiencing abusive treatment, and lacking resources, individuals experiencing chronic homelessness face a mortality rate that is four to nine times higher than the general population (U.S. Interagency Council on Homelessness 2013).

In addition to exacerbating dangers and creating further barriers to accessing resources (Hodgetts et al. 2008; Wright 2000), these punitive policies infringe on the public's right to the city (Harvey 2008; Lefebvre 1991; Mitchell 1997). The right to the city is an idea and movement coined by Henri Lefebvre, who described it as "a cry and a demand" for all inhabitants to participate in accessing, using, and transforming urban spaces (Lefebvre 1991, p. 158). David Harvey (2008) explains, "The freedom to make and remake our cities and ourselves is...one of the most precious yet most neglected of our human rights" (p. 23).

\section{"Insiders" and "Outsiders": The Narrative Construction of Belonging in Public Space}

Who is granted the right to the city? According to moral exclusion theory, the provision of rights and justice is determined by membership in the moral community, in which the boundary between those deserving and undeserving of rights is determined by the scope of justice (Opotow 1990, 2006). Those classified inside the scope of justice are considered worthy of protection and fair treatment, whereas those classified outside the scope of justice are considered a "plague or threat," denied equal rights, and even "subject to punishment and deprivation" (Opotow 1990, p. 2; Opotow 2006, pp. 305-306). Research with policymakers in New Zealand suggests that anti-homeless ordinances are grounded in narratives that exclude homeless individuals from being considered citizens or legitimate members of the public, and therefore they are not considered entitled to public safety or access to public space (Laurenson and Collins 2006).
Boundaries drawn in public space between insiders and outsiders are mediated through discourse and correspond to differential relationships to power (Di Masso 2012; Dixon and Durrheim 2000; Rappaport 2000). Empirical studies suggest that ideas about who is considered a legitimate user of space and what behaviors are considered appropriate are reproduced through dominant narratives of exclusion (Dixon and Durrheim 2004; Dixon et al. 2006). The dominant narrative in the US is rooted in an ethic of individualism and meritocracy that portrays poverty as the outcome of negative individual attributes, such as laziness and immorality, rather than structural disadvantage, such as classism, racism, and sexism (Bullock 2008; Limbert and Bullock 2009) and rising income inequality (Hochschild 1995; Krueger 2012). Consequently, attempts of displaced groups to meet their basic needs in public - seeking shelter, bathing, and disposing of waste-are not seen as symptomatic of deep underlying social injustice but as the result of deviant behaviors that threaten the local economy, defile the aesthetic and order of the street, and disrupt the enjoyment of the consumer experience (Amster 2003; Mitchell 1997). By delegitimizing and displacing social groups seen as disrupting the status quo, dominant narratives act to maintain the existing power structure. As Lott (2002) notes, “...The process of 'othering,' of defining a 'group as morally and/or intellectually inferior,' provides advantages to the dominant group. These advantages are obtained by maintaining barriers that restrict access to resources by the others, thus easing access by those who are like oneself" (p. 108). For example, research conducted by Barnes (2000) with English participants discovered that normative constructions of space and citizenship as sedentary contributed to discursive constructions of "travelers" as deviant and "out of place." These narratives were used to justify the need to control and exclude traveling communities (see also Barnes et al. 2004). Tileagă (2006) found that dehumanizing and delegitimizing discourse used by Romanian professionals when talking about ethnic minorities worked to exclude and discriminate against Romanies by constructing them as "uncivilized." In addition, discursive data gathered by Dixon and Durrheim (2004) from users of a desegregated South African beach, where black South Africans had until recently been excluded by the use of policing and "whites only" signs, revealed that white respondents expressed feeling unsafe and displaced, narrating the presence of racial "others" as disruptive and transgressive.

Although research has increasingly begun to document the way in which spaces are constructed to exclude individuals on the basis of social categories, little work has focused directly on how unhoused community members experience and make meaning of exclusion and how they respond. In addition, no studies have simultaneously 
examined policy discourse, community discourse, and personal narratives of space and its regulation. The aim of the present study is to interrogate the contested negotiation of boundaries in public space, as specifically experienced by individuals experiencing homelessness in a US context. We examine our questions through the theoretical lens of narrative engagement (Hammack and Cohler 2009)-the idea that individuals engage with multiple, competing discourses about social categories, and that these discourses are not neutral with regard to political and historical power (see also Hammack 2011, 2014; Hammack and Pilecki 2012). A key premise of this theory is that individuals make sense of their own experiences through dialogue with existing collective narratives, which they may reproduce or resist (Hammack 2008). Empirically examining discourse at both the community and personal levels of analysis allows us to interrogate this process and thereby to examine not just individual experience but also social processes of stasis and change (Hammack 2011; Hammack and Pilecki, 2012). We also situate our analysis in theories of moral exclusion (Opotow 1990) and spatial justice (Harvey 2008; Lefebvre 1991; Mitchell 1997), offering an interdisciplinary analytic framework that will contribute to concrete applications of these theories and enrich existing literature on narrative and identity by exploring the role of place, which is all too frequently neglected in social psychological research (Dixon and Durrheim 2000).

\section{Methods}

\section{Research Context}

The geographical setting for this study was the downtown area of the city of Santa Cruz, located in the southern Bay Area of California. Several factors made Santa Cruz a prime location for the focus of this study. First, the city has an extremely high rate of homelessness per capita (U.S. Department of Housing and Urban Development 2013, p. 11), with 1351 homeless individuals counted in the city of Santa Cruz during the 2013 point-in-time count (Applied Survey Research 2013). Strikingly, only $18 \%$ of people experiencing homelessness in Santa Cruz County were sheltered (either in transitional housing or an emergency shelter), while the majority were living on the street, in cars, camps, or abandoned buildings (Applied Survey Research 2013). This is driven by the high cost of living in a city reported to be the sixth most expensive metropolitan area to rent in the US (NLIHC 2014). Despite the numerous service agencies dedicated to providing support to the homeless population, only around 200 beds are available on a given night (this number increases to 300 in winter months; Sleeper 2014). And, despite the city's progressive reputation (Gendron and Domhoff 2009), Santa Cruz's municipal ordinances contain harsh anti-homeless legislation, which prohibit sitting on downtown sidewalks within 14 feet of any building, lying on public sidewalks, sitting on public benches for more than $1 \mathrm{~h}$, lying on a public bench, sleeping outdoors or in a parked vehicle, and covering up with a blanket in public (Code Publishing Company 2014). Violating these ordinances results in an infraction, and multiple infractions result in a misdemeanor, with punishment including fines and/or arrest.

The high visibility of unsheltered homeless individuals in a city that largely relies on revenue from tourists and university students makes homelessness a fiercely contentious issue (Pascale and West 1997). As the city's central business district, downtown is thus an especially controversial site heavily regulated by the presence of police and private security and by ordinances limiting the noncommercial use of the street and sidewalks. The connection between homelessness and issues of belonging, identity, and safety downtown is frequently debated in the media and public fora (e.g., Onishi 2013). This debate intensified after a series of violent crimes in 2012, including the shooting of two police officers. City officials responded to concerns over public safety by appointing 15 community members to a Public Safety Citizen Task Force, which met and deliberated for 6 months to produce a list of policy recommendations comprising the 2013 Public Safety Citizen Task Force Report. The contents of this report were included in the present analysis.

\section{Participants}

Data collected for the purpose of this study included (a) semi-structured, in-depth interviews with housed and unhoused community stakeholders, (b) ethnographic observations, and (c) text from the Santa Cruz Public Safety Citizen Task Force Report (2013). The first author conducted ethnographic fieldwork between 2013 and 2014 in order to develop familiarity with local public places and community conversation around homelessness. Scholars have noted that ethnographic methods are well-suited to explore how cultural, historical, and ecological context affect lived experiences and "how social processes... within a setting create norms, ultimately shaping personal stories and community narratives" (Case et al. 2014, p. 62). This process involved recording fieldnotes after spending time with guests at free dinners held at local churches and outside in popular downtown public spaces, attending city council meetings, activist meetings, and public fora pertaining to issues of homelessness and public safety, and examining local ordinances and public documents dealing with the framing and regulation of homelessness in public space (specifically, the Public Safety Citizen Task Force 
Report 2013). We obtained public records of Santa Cruz City Council meeting agendas, minutes, and video recordings online (see City of Santa Cruz 2013).

We recruited interview participants using purposive nonprobability sampling. Participant recruitment was an iterative process. In order to reach a diverse sample of housed and unhoused stakeholders, the first author first tabled with informational materials displayed at several downtown locations, including the weekly farmers' market, the public library, and free weekly dinners held at two local churches. Interested community members were given a more detailed explanation of the study and invited to participate in an interview. We also made targeted attempts to speak with members of an influential community organization founded in 2009 whose reported mission is to make the streets of the city safe. We sent messages to the organization's email address and Facebook page but yielded no response. We then posted an announcement soliciting participation in the study to a local neighborhood social networking website. Finally, we reached several members via "snowballing" methods.

Thirty members of the Santa Cruz community participated in an interview. Of those community members, 19 had experienced homelessness at some point, and 14 were unhoused at the time of the interview. Of those who were unhoused at the time of the interview, participants' ages ranged from 18 to 54, with a median of 31 years. Four identified as female and 10 identified as male. Participants' racial/ethnic backgrounds included Black/African American $(n=1)$, Native American $(n=3)$, and White/European-American $(n=10)$. Participants who were unhoused at the time of the interview had lived in Santa Cruz an average of 16 years.

Of those who were housed at the time of the interview, participants' ages ranged from 30 to 69 , with a median of 49 years. Ten identified as female and 6 identified as male. Participants' racial/ethnic backgrounds included Black/ African American $(n=1)$, Hispanic/Latina $(n=1)$, White/European-American $(n=13)$, and dual heritage (Asian American and White; $n=1$ ). Participants who were housed at the time of the interview had lived in Santa Cruz an average of 25 years.

\section{Researchers}

Ethnographic observations and interviews were conducted by the first author, a middle class white woman and graduate student in social psychology. She became engaged in advocacy and action around issues of economic justice and housing after working as a service provider at a drop-in center for youth experiencing homelessness, and has since been involved in conducting research on homelessness. She primarily uses qualitative and narrative methods, taking meaning to be socially constructed as well as inherently personal, social, and political, and thus a powerful tool for investigating issues of social justice. She lived in the Santa Cruz community for approximately 2 years at the time of conducting this study and has not experienced homelessness, so she was in several ways positioned as an "outsider" to the local context and the situations she sought to study. Throughout this project, she regularly wrote reflexivity memos in order to consider her own social positionality and her relationship to the groups with which she interacted. The second author, a middle class white gay male, has extensive experience using qualitative methods to study the lived experience of groups experiencing social injustice, including racial and ethnic minorities in the U.S. (e.g., Ramirez and Hammack 2014), groups living under military occupation (e.g., Hammack 2010), and sexual and gender identity minorities (e.g., Hammack and Cohler 2011). He is committed to the production of knowledge intended to redress issues of injustice and is deeply committed to the eradication of economic inequality.

\section{Interview Procedure}

Before starting the interview, we gave each participant an informed consent form to sign, which was read aloud, explaining that participation was completely voluntary, that participants would be welcome to leave at any time without penalty, that confidentiality would be maintained, and that the interview would be audio-recorded. Participants were informed that all identifying information would be removed from transcripts and that these the text would be read by others and could be made available to the public. All procedures were approved by the Institutional Review Board of the University of California, Santa Cruz.

Interviews were conducted by the first author. To begin the interview, she first asked participants to provide a brief overview of their life story by drawing a line representing their life from birth to the present, rising when things were good and falling when things were bad. This exercise is modeled on Runyan's (1980) Life Satisfaction Chart and has been used in life-story narrative research to allow interviewees to construct the form of their life stories (e.g., Hammack 2006; see Lieblich et al. 1998). Participants were then asked to share stories of positive and negative experiences of downtown Santa Cruz, what they liked and disliked most about downtown, how they used downtown space, feelings of community belonging and public safety. Participants were also asked about their attitudes and beliefs regarding homelessness in Santa Cruz and their perceptions of the city's service provision and law enforcement. Unhoused community members were asked about their experiences of homelessness in public space 
and obstacles and resources they had come across, and how they would characterize their social interactions.

Interviews lasted an hour on average and were recorded on a small audio-recorder and later transcribed. Participants chose what name they would like to go by in the report and received a $\$ 10$ gift card to a local business to thank them for their participation.

\section{Analytic Strategy}

Data analysis was conducted using thematic analysis (Braun and Clarke 2006) situated in a constructionist-interpretivist paradigm, in which meaning is understood to be socially and culturally constructed through discursive acts (Bruner 1990; Gergen 1985; Tappan 1997). Interview data was initially given an inductive, bottom-up reading and coded line-by-line for idiographic (i.e., person-centered) meaning using qualitative data analysis software, NVivo. Data was then re-read and organized into higher-level, theoretically derived themes based on patterns seen across participants and informed by our specific research interests in public space, homelessness, and moral exclusion. This iterative process involved multiple readings of the data in order to define, distinguish, and refine themes, developing a thematic map to situate data within a larger story (see Fig. 1). Following a hermeneutic approach to qualitative data analysis (e.g., Josselson 2004), the two authors met routinely during the data analytic phase to come to consensus on the meaning and interpretation of data.

This study relied on data triangulation methods, as outlined by Denzin (1978), in order to place participants' narratives in dialogue with one another and to investigate how community members' informal speech engaged with the rhetoric used in formal public documents-in this case, the 2013 Public Safety Citizen Task Force Report. The goal of triangulation is not convergence or the elimination of bias, but to capture plural and contested perspectives from multiple sources of data in order to provide a richer, more holistic, complex picture of social phenomena (Mathison 1988).

\section{Findings}

We organize the presentation of our findings in such a way as to first outline the policy and community discourse on public space through analysis of the Public Safety Citizen Task Force Report (2013) and public comments made during the City Council meeting in which the report was presented (City of Santa Cruz 2013). We then demonstrate the ways in which individual community members engaged with this dominant community discourse through an analysis of interview data. This organization elucidates the way in which individuals engage with master narratives of public space and its access by first revealing the elements of those narratives and then the way in which individuals appropriate or repudiate them in their own personal narratives of space.

\section{Legitimizing Exclusion: Institutionalizing Boundaries as "Protection" Through Public Policy}

The 2013 Public Safety Citizen Task Force Report, as an official document addressing the perceived escalation in crime and disorder in the city, demonstrates the ways in which dominant narratives construct boundaries of exclusion through the framing of homelessness as a threat to the public safety and economic vitality of downtown. These boundaries were then institutionalized through policy recommendations calling for increased regulation of public space.

The framing of homelessness as a threat to public safety was accomplished through the discursive construction of unhoused individuals as criminal and unclean. The report states,

Many in Santa Cruz believe that the community's open spaces and business districts are not enjoyable for several reasons. A high concentration of homeless people live and camp in open areas...near Downtown and the beach area. At times, this homeless population comes with erratic behaviors, trash, sleeping materials and human waste. Behaviors not perceived as normal can be off-putting to many and even frightening to others... This fear translates into an aversion to visit Downtown. (p. 22)

In addition to displays of non-normative and "frightening" behaviors, the presence of homeless individuals was portrayed as a threat to public safety by defiling and polluting public space with improper waste disposal, litter, hypodermic needles, and encampments. This is illustrated in the following excerpt:

Santa Cruz is burdened by a segment of the homeless population that is responsible for escalated disorder and public health concerns. Disruptive behaviors and flagrant disposal of human waste, illegal trash and hypodermic syringes, oftentimes symptoms of substance abuse and mental illness, are a major public health concern and exacerbate fear of crime in Santa Cruz. (p. 26)

Boundaries of exclusion were also constructed in this document by framing unhoused individuals as a threat to the economic vitality of downtown. Perceptions of the unhoused as unclean and criminal, believed to elicit 


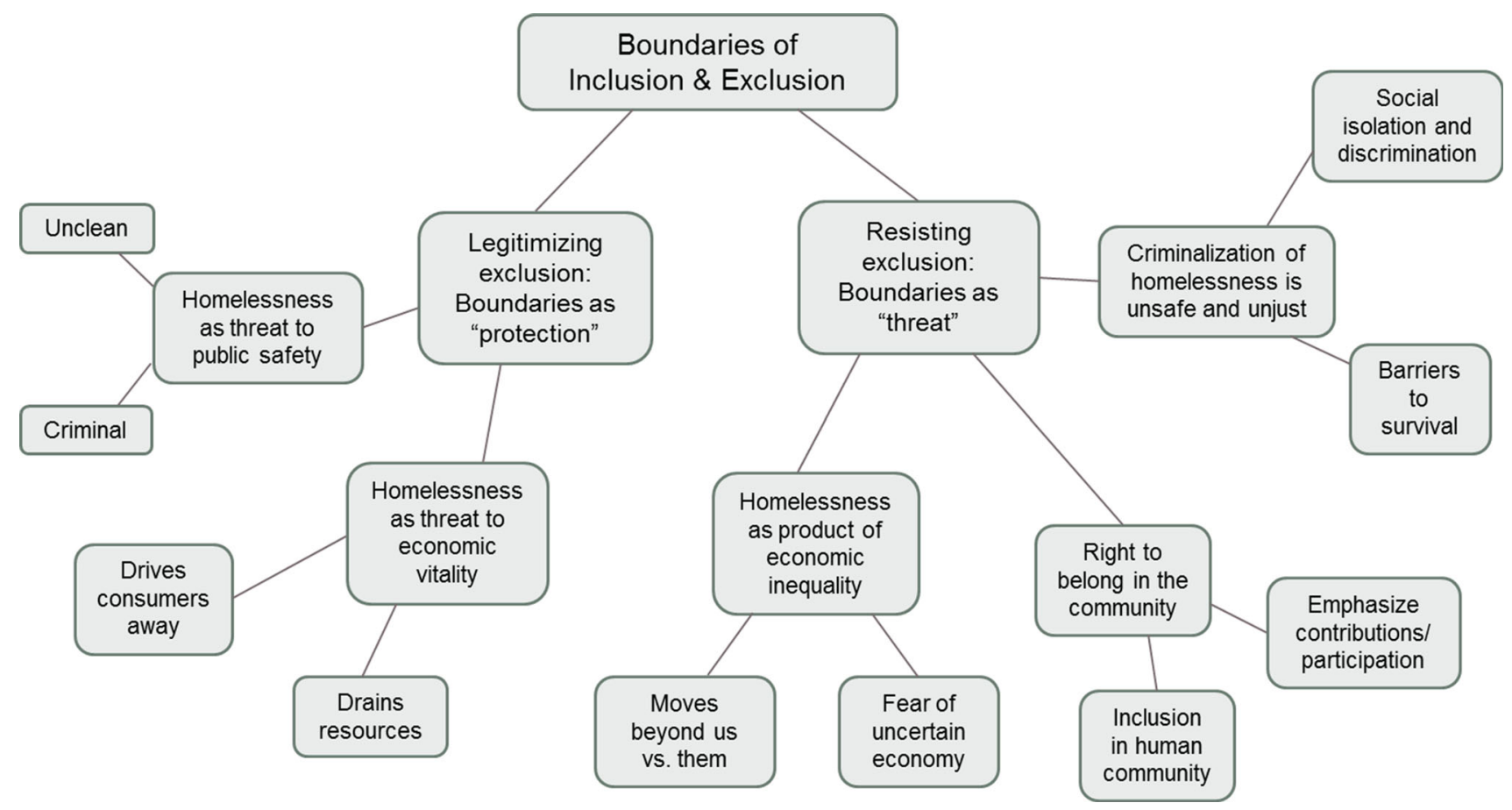

Fig. 1 Thematic map depicting organization of data into themes and subthemes

responses of fear and disgust, were seen as "driving away" legitimate consumers of public space.

Aggressive panhandling, public intoxication, and other unpredictable behaviors along Pacific Avenue and in the beach area are perennial problems and have diminished the potential of the community's most prized business district to flourish and grow economically. (p. 22)

Furthermore, the framing of the unhoused as a threat to the city's economic vitality was supported by the argument that this population represented a drain on public resources. "Calls for service are at an all-time high," the report claimed (p. 41), citing the high rate of repeat offenses and arrests for "public nuisance" and "quality of life" crimes, noting that homeless individuals accounted for around $40 \%$ of arrests and $30 \%$ of citations in the city in 2012 .

In an attempt to manage the challenges around our public spaces and business districts, the City has adopted several municipal codes ordinances to regulate public nuisance behavior. However, the current enforcement and accountability strategy of these ordinances is clearly not working. Many in our community witness the same individuals day in and day out behaving in erratic ways, causing disturbances, harassing others, and getting cited for municipal code infractions without consequences.
This repetitive behavior and the perception that there is no accountability are genuine concerns and a significant drain on Police, Park and Public Works staff resources. (p. 23)

In this excerpt, boundaries of exclusion in the form of ordinances are legitimized by framing the city's public safety problem as a lack of regulation in public space and lack of accountability for violators. "Tolerance without accountability is a cause of the City's current safety concerns," the report reiterates (p. 2). Without increasing surveillance and accountability, the report argues, lowlevel crimes quickly escalate into violent crimes, noting that "a segment of the homeless population is susceptible to escalating criminality" (p. 34).

In accordance with the framing of the problem, the report's proposed solution advocated increasing the regulation of public space and the severity of punishment for those perceived as out of control and out of place, elevating infractions for illegal camping and depositing of waste to misdemeanors, demanding that service agencies construct a gate around their perimeters and utilize a photo identification system, and "eliminat[ing] services to persons identified as chronic offenders who threaten public safety" (p. 43). Thus, the criminalization of homelessness was advanced as a preventative measure necessary to ensure public safety.

Public policies reflect dominant community narratives on public safety. Public statements made in the City 
Council meeting (City of Santa Cruz 2013) dedicated to the discussion of the Public Safety Citizen Task Force Report illustrate the ways in which boundaries excluding the unhoused from public space are mediated through speech. As in the Public Safety Citizen Task Force Report, the notion that the unhoused represent a threat to the safety and economic vitality of downtown emerged in these public comments as justification for exclusion. "It is very disturbing to me that our town is dirty and unsafe," said a local real estate agent.

If the downtown dies, there won't be any place to panhandle. It will be a dead environment. I really hope that something will be done about people sleeping on the sidewalks and sleeping in public places. I love the idea of a shared community environment. I'm sorry, I don't want to share it to the death of our economic survival. I don't want to share it so that I'm afraid to walk down Pacific Avenue... I hope that something is done so that law enforcement can at least make our sidewalks a place that is appetizing to go.

These public statements reflect a dominant narrative that designates the prime purpose of downtown as a space of consumption, one that should be comfortable, aesthetically pleasing, and "appetizing" to those with expendable income. In contrast, the unhoused poor are cast as threatening, undeserving, non-contributing outsiders who take and do not give back. "I just feel like I have to speak out in defense of the citizens of this area," said one woman (City of Santa Cruz 2013). "We pay taxes and we have really, really given to this town. And we have many, many, many people coming here not be responsible and not give back."

In this dominant narrative, the homeless population represents an attack on the city's boundaries: allowing "insiders" to be victimized by parasitic "outsiders." "I've been worried about the increased crime in this community for quite a while," one local man said (City of Santa Cruz 2013). "Almost every bench is filled with transients and people who obviously have mental issues. There's not places for us citizens to really sit-it's just overrun." This rhetoric suggests competition over scarce resources and likens homelessness to an infestation, urgently requiring regulation. Hence, the spatial exclusion of the unhoused is justified through discursive exclusion of the unhoused from consideration as members of the "citizenry" or "public," undeserving of rights or protection.

In sum, our analysis of the official policy document and public comments on it revealed a dominant community narrative of exclusion for the unhoused with regard to public space. Discourse about unhoused individuals contained delegitimizing language, framing them as community "outsiders" unworthy of the same access to public space as housed individuals. Public space was conceived as largely intended for consumption, as discourse focused on the economic role of public space in the community. In order to examine the extent to which housed and unhoused individuals in the community engaged with this dominant narrative, we turn now to our analysis of the interview data.

\section{Maintaining Inequality: Reproducing Master Narratives of Exclusion}

The concept of master narrative engagement (e.g., Hammack 2011) illuminates the ways in which housed and unhoused participants made sense of dominant narratives of exclusion through their personal narratives. We provide an analysis of how participants maintained existing barriers of exclusion against unhoused individuals by reproducing the dominant narrative that the unhoused threaten the safety and economic vitality of downtown. These narratives reinforce an "us" versus "them" discourse, pitting the interests of the unhoused poor against those of the middle class.

The notion that homeless individuals threaten the safety of downtown due to non-normative behaviors and engagement in criminal activity was reproduced by Gigi, a 56 year old housed woman. "There are people that are dangerous that are being given services and not taking part of any kind of real psychological upkeep... And we, as law-abiding, good citizens, are in jeopardy..." She went on to say,

There's the shelters and services and they are serving people I know for a fact are, you know, running from the law and have done horrible things to our community members. A lot of homeless people I understand have not only been down on their luck but they've made bad decisions. You know, were they harmful to other community members and do we really want to put them up in our community? Or do we say, you know what? Hit the road, Jack.

Gigi's language paints a picture of "law-abiding, good citizens" threatened by unhoused criminals who lack control and morality, serving as evidence for the need to exclude them from the community.

The construction of unhoused individuals as a threat to the economic vitality of downtown also emerged as a key theme in these interviews, mirroring the rhetoric of the dominant discourse disseminated in the Public Safety Citizen Task Force Report. Repeatedly, unhoused community members were framed as "takers" who benefited unjustly from the labor of others (see Bullock and Reppond, in press). "It's discouraging to see people that don't have 
anything to do," reflected Charlie, a 56 year old housed woman. "If you want to live off the society or the system, you know, it's a fine line how to do it without burning your bridges, without pushing so far, so hard that, you know, then the City Council has to come up with another measure about what to do because they've had too many complaints." Here, Charlie suggests that enacting restrictive measures and surveillance against the unhoused is justified due to behavior that does not respect the boundaries of what is appropriate and fair. For many, including Charlie, this justification was connected to the belief that visible homelessness discourages legitimate users of downtownconsumers and tourists-and is therefore bad for the economy: "I know that everybody is concerned with the amount of panhandlers and homeless and all of that because we are a tourist town.... It does matter, because it does discourage people."

It is worth pointing out that prejudiced views against homeless individuals were not only reproduced by housed participants. Several unhoused participants also employed this speech, often to distance themselves from perceived negative or stereotypical behavior from other unhoused individuals such as aggressive panhandling, littering, or drug use. Jotham, a 37 year old unhoused man, for example, explained, "I dislike the fact that the place has been dog-piled by a bunch of dysfunctioning homeless people who will treat the place like they're in jail... You have a bunch of people who are unregulated being out of control and looking-making the whole group look bad, and that's not right." Although this language reproduces the idea that unhoused individuals are unregulated, it is important to note that the survival of persons experiencing homelessness often depends on conforming to dominant ideals of "deservingness" to receive much needed resources and services from those in positions of power.

Language framing the unhoused as a threat to the safety and economic vitality of the community worked to maintain the exclusion of those experiencing homelessness from public space by contributing to an "us" versus "them" rhetoric. "It's just like they [people on the street] own the joint, you know?" expressed Maria, a 40 year old housed woman. "The people are um, like how do you say, entitled. It's almost like this is, they're, this is their space, you know." In this framing, the protection and rights of the unhoused were seen as detracting from the protection and rights of the middle class and elite users of public space. "Number one needs to be the business and the person trying to get into the business," Maria explained. "It's not a place where everyone should be able to do whatever they want, whenever they want." The perception of boundaries under attack was used to justify the need for stricter policing and regulation.

\section{Resisting Exclusion: Contesting Boundaries}

Findings from the interviews also revealed resistance to boundaries of exclusion. This section outlines examples in which interviewees, primarily but not exclusively those who had experienced homelessness, contested the notion that the unhoused are outsiders, threats, or a drain on public resources and condemned policies that criminalize homelessness. We identified three core themes to describe the ways in which participants contested boundaries: through discourse indicating that the criminalization of homelessness is unsafe and unjust, through discourse indicating the right of the unhoused to belong in the community, and through discourse reframing homelessness as the product of economic inequality.

The construction and policing of boundaries between outside and inside, purportedly designed to "protect," was found to threaten the safety and dignity of the unhoused poor by constructing barriers to survival. In this discourse, restrictions on sleeping, sitting, and bathing in public spaces severely limited the ability of unhoused participants to meet their most basic needs. Sean, a 53 year old unhoused man, illustrated this pattern:

You can't go to the bathroom in your own bathroom, you gotta to go to the public bathroom, you know. And there are people bathing and that's a pressure and people you know, screaming at you about being homeless and wrecking the bathrooms, and people who just stand there staring at the door telling you to hurry up, hurry up... Uh, sleeping. You're always in jeopardy of being caught sleeping by either a private party or the police... It's very, very, very draining.

Dehumanizing policies and discourse were also found to threaten the survival of the unhoused through social isolation and discrimination. Unhoused participants commonly reported feeling othered in social interactions downtown. "They always look at us like we're garbage," explained Vic, a 46 year old unhoused man, "like we don't belong here." Because behaviors associated with meeting basic needs in public space were constructed as inappropriate and even "criminal" in the dominant discourse, unhoused community members were often subjected to discrimination and even violence. "There would be people driving by, cussing us out, telling us to leave their town and so on," Vic explained, "And we tried to ignore them. But when they start throwing beer bottles and balls and stuff at us, we can't ignore that shit." These narratives of lived experience point to boundaries of exclusion and the consequent criminalization of homelessness, not as measures of protection but as weapons of violence and injustice.

The second way in which interviewees contested boundaries of exclusion was by asserting their right to 
belong in the community. Gary and his wife, Pam, who were interviewed as a couple, referenced their humanity as the reason they deserved inclusion. "We still have hearts and we have a conscience," stated Pam. "We're still humans, we aren't garbage. We're not to be tossed aside. We're contributing people." "We're not a throwaway people," reiterated Gary. "You can't, you know, put us all in a concentration camp, like Hitler did." Pam and Gary, as well as many other unhoused participants interviewed in this study, emphasized that belonging to the "human" community trumps any other classification or status, thus entitling them to rights and protection from harm.

Unhoused participants also proclaimed their belonging in the local community by asserting their contributions. The desire to be recognized as someone with the ability to give was expressed by many participants, such as Sean, who eagerly shared his ideas for bettering the community. Sean firmly resisted the notion that unhoused community members were a drain on public resources and instead pointed to stress-inducing housing and low-wage labor conditions as the main inhibitors of community participation. "There is so much beautiful, creative people here that can make things," he observed, "and those people are on the streets ((laughs)) you know, or working down at McDonald's or Taco Bell... They don't have energy to be creative anymore, they're just trying to make a few bucks."

Like several unhoused participants, Sean was also quick to point out that he was a native to the city: "I'm not here to destroy the community, this is my community. I grew up here. I love this town. I don't wanna see that all destroyed." In this interview excerpt, Sean positions himself as a passionately invested member of the community rather than its enemy. He also resists his classification by the dominant narrative as a "transient" who has come from elsewhere to take advantage of services.

Finally, participants resisted boundaries of exclusion by reframing homelessness as a product of economic inequality - a collective and systemic issue-rather than locating the problem in the bodies of homeless individuals. This theme is defined by language that moved beyond the "us" versus "them" rhetoric. Multiple participants challenged the boundary that separated the housed from the unhoused by alluding to the ease with which homelessness can happen. "A lot of these people are two or three paychecks away from being homeless," Gary observed.

This theme was expanded upon by Ted, a 61 year old male participant. As someone who was vulnerably housed and had previously experienced homelessness for many years, Ted was intimately familiar with the reality that homelessness is a situational experience rather than a static category:
You could be there the next day, you know, it's like, it's not something that you plan... You'll be working one day, the next thing you know... all of a sudden you're homeless... You're living day to day, trying to survive, and you're trying to save up money to get a place, and there's no way you can do it.

In these narratives, homelessness is framed as the outcome of an uncertain and unequal economy, disrupting the dominant myth of the US as a fair and prosperous society. This point was articulated by C.B., a 47 year old man and long-time Santa Cruz resident who had just recently moved into subsidized housing after experiencing homelessness for several years:

Homeless people are a mirror held up to society that says, that shows them immorality. And they don't like to look at that... They don't like to think, 'I could be homeless, too, someday.' So they're afraid.

C.B.'s narrative reveals the uncomfortable reality that as the barriers erected to protect class privilege grow ever higher, more Americans are at risk for falling into poverty (Bullock 2014; Lott and Bullock 2007). Contesting boundaries of exclusion by discursively reframing homelessness as an issue of inequality was not voiced exclusively by unhoused community members. For example, Jerry, a housed downtown business owner, reinforced the idea that the "problem" of homelessness is actually a problem of the concentration of wealth and erosion of the middle class:

I honestly think this issue of class disparity is the biggest issue for Santa Cruz. There's a handful of people that own everything and everybody else is just fighting for scraps... They're fighting with each other and then also with people who have very little to nothing, and trying to like to sweep them out and not ever wanna see them anymore. So I think really actually recognizing what the root of the issue is, is that there's a huge income disparity, which is I think a national issue as much as it is a local issue.

These narratives resist the notion that the unhoused population poses a threat to public safety. Rather, these narratives suggest that the unhoused are feared as a symbolic threat to the myth of upward mobility. However, as many participants suggested, eliminating the unhoused from public space only exacerbates the erosion of rights and democracy. "We need to not care whether those rights are the rights of housed people, homeless people, men, women, whatever, and we need to support them equally, we need to be more active when those rights are violated," asserted Jotham. "We have more recourse and we need to have more willingness to work together to make solutions 
happen." These statements reveal resistance to boundaries of exclusion. "We're not separate," Ted stated emphatically:

We're all in this together, even though they tell us we're not, we're all-I really do believe we're all in this together... People who have a sense of camaraderie and care for each other, have a sense of, wanting to share a common goal... will bring unity, something that will inspire you, you know, something that you wanna just hold on to and embrace it and say yeah, I'm a part of. You know, and be a part of, be recognized. To know that you're important. To know that your voice can be heard.

These stories express a demand for the right to the city and the violation of this right by the privatization of public space. "There's not a spot on Earth that I could stay for free," said Leonard, a 34 year old unhoused man, "and that's a fucking crime... we should all have a place to live on Earth. It's not such a strange idea, actually." He continued on to say,

I mean, why are people homeless? I mean, it's because everything else is privatized... A certain amount of people are bound to be homeless because of the economic conditions of society. And until we actually have land that's actually available for people to stay on, I mean, everybody's, there's always going to be people who are homeless.

Similarly, Raven, a 20 year old unhoused woman, resisted the boundaries posed by policies of exclusion by labeling them as unjust, irrational, and immoral:

I've been told by the police department that there's nowhere for me to sleep outside. I can't fall asleep anywhere. That just tells me that they want you out, but guess what? They tell me that in every city I've been in... How are you gonna tell me I can't sleep over here not bothering nobody? I think that's blasphemy... There are more vacant homes than there are homeless people... The system fails, it doesn't take care of everybody, so if you really want it, your homelessness, to not be an issue, open some doors and give us some opportunities.

\section{Discussion}

Using data triangulation to explore the text of the Public Safety Citizen Task Force Report, ethnographic fieldnotes from a city council meeting, and interview data with housed and unhoused community members, this study illuminates the ways in which policies regulating public space construct boundaries excluding the unhoused from public space. Using the concept of master narrative engagement, this analysis also illustrates how housed and unhoused community members maintain and resist boundaries of exclusion, revealing the highly contested nature of public space and the ways in which individuals engage with master narratives.

As our findings reveal, boundaries of exclusion are spatially and discursively constructed through dominant narratives that cast the presence of the unhoused as a threat to the safety and economic vitality of downtown public space. In this discourse, the description of public space as overly unregulated and permissive was used to justify the need for increasing regulation and punishment for violators through the criminalization of homelessness. Such language, and the beliefs it reflects, constructs public space as a space of consumption and consequently designates those with expendable income as legitimate users of public space (Barnes et al. 2004; Dixon et al. 2006; Ferrell 1997; Mitchell 1995). Behaviors associated with the survival of the unhoused, however, were designated as public nuisances, seen as out of control and out of place (Wright 1997). This study builds on previous research that discusses how the punishment or removal of marginalized groups is justified through discourse and policies that construct such groups as transgressive "outsiders" (Barnes 2000; Barnes et al. 2004; Dixon and Durrheim 2004; Tileagă 2006).

Our analysis suggests that while the boundaries articulated here are framed as necessary to protect the collective well-being of the community, public resources and spaces are being appropriated for the profit and pleasure of middle class and wealthy individuals, contributing to the gentrification of public space. The definitions of "public safety," "public health," and "public resources" as referenced in these claims only make sense if members of the homeless population are excluded as members of the "public," as observed by Laurenson and Collins (2006). Thus, the exclusion of the unhoused from public space also corresponded with the exclusion of the unhoused from what Opotow (1990) calls the moral community. Discourse casting the unhoused as "outsiders" whose presence was seen as violating the safety, cleanliness, order, and vitality of public space worked to strip the unhoused of their rights to fair and equal treatment (Amster 2003), including the right to the city. Such exclusion renders social class invisible and reproduces inequality by marginalizing the lived experiences of the unhoused poor.

Interview data from this study also showed the emergence of a powerful counterstory-one that contested the boundaries of exclusion drawn by the dominant narrative. An exploration of the lived experiences of unhoused community members suggested that policies criminalizing 
homelessness may not protect public safety. Rather, they might perpetuate dehumanization and violence. Furthermore, they suggest that the criminalization of homelessness may not protect economic vitality but rather legitimize economic inequality. These narratives suggest such boundaries of exclusion, which foster hostility and division and fail to address the growing crisis of economic inequality, contribute to the larger threat to public safetypoverty.

These narratives of resistance affirm the right of unhoused community members to belong in the community and move beyond an "us" versus "them" rhetoric, relocating the problem of homelessness from within the bodies of those experiencing it to the economic and political structures that produce and maintain inequality. This language redefines homelessness from the consequence of excessive permissiveness and a lack of regulation to the concentration of wealth and erosion of the public due to privatization. Such findings contribute to a growing body of literature highlighting the importance of resistance narratives for marginalized groups in contesting stigmatizing dominant narratives, affirming their dignity and worth, and claiming equal rights (see Case and Hunter 2014; Opsal 2011; Sonn and Fisher 1998).

This study suggests that the privatization of public space functions to reproduce class inequality by restricting access to resources and restricting interactions between diverse groups of people. Understanding the psychological processes by which ideology translates into social structures and corresponding social behaviors helps to reveal the opportunities that citizens have to take an active, participatory role in shaping public spaces to build more democratic, pluralistic communities. This study highlights the importance of the right to the city - the right to use and transform public space-and how critical this is for accessing resources, social interaction, and democratic participation (Di Masso 2012).

Our study offers a novel contribution to the literature by applying social psychological theories of moral exclusion and narrative engagement to an analysis of spatial justice. Applying moral exclusion theory (Opotow 1990, 2006) in this study, we can see how the construction of homeless persons in shared public space as threatening, immoral, and undeserving functioned to exclude the unhoused both from shared physical space and from the scope of justice. This study makes an important empirical contribution to moral exclusion theory by exploring the ways in which delegitimization and exclusion happen in a particular spatial, cultural, and political context through everyday discursive acts (Bakhtin 1981; Tileagă 2007). As Tileagă (2007) reminds us, "It is through language practices that relations of power, dominance and exploitation become reproduced and legitimated" (p. 722).
Narrative perspectives in social and personality psychology have disproportionately focused on analyses of personal discourse and life stories, only recently drawing links to cultural or community narratives (e.g., Hammack 2008; see also Hammack and Toolis 2014). Our study is part of a growing movement in psychology that uses narrative methods to link lived experience to social categories and social structure, seeking to reveal the way in which social categories confer relative power and legitimize injustice (e.g., Hammack 2011; Toolis and Hammack 2015). This research supports the notion that dominant narratives may serve a "palliative" function by reducing guilt or discomfort about inequality, thus working to justify the status quo (Jost and Hunyady 2003). Importantly, we also demonstrated that such narratives are not monolithic but highly contested.

Finally, this study contributes to theories of spatial justice. Critical spatial theorists hold that there is a dialectical relationship between space and social relations (Lefebvre 1991). This study illuminates ways in which social actors construct space through discourse by negotiating the purpose of public space, what behaviors are permitted, and who belongs. Furthermore, the findings presented here highlight the important psychological implications of spatial boundaries in the ways in which unhoused community members are affected by, make meaning of, and resist those boundaries.

In addition to its novel contributions to theory, this study benefitted from a rigorous qualitative method that utilized multiple sources of data, from official policy documents to ethnographic observations and individual interviews. The triangulation of data from these multiple sources allowed us to interrogate a social problem-the use and regulation of public space - at multiple levels of analysis. Analyses in social, community, and environmental psychology benefit from methods that can facilitate links among the discursive, political, and personal levels in order to understand how social processes of exclusion and resistance take shape within a particular cultural, historical, and ecological context (Case et al. 2014).

In spite of the theoretical and methodological strengths, there are several limitations to this study that bear mentioning. First, it is important to note that there were demographic differences between participants who were currently unhoused or had experienced homelessness and those who had not, reflecting differences in social identities. Participants in the sample who had experienced homelessness were more likely to be male, were younger, and had lived in Santa Cruz for fewer years on average compared to participants who had not experienced homelessness. Although the goal of this study was to explore the ways that social actors engaged with dominant narratives that existed in the community rather than probe group 
differences, the differences in social identities between participants who were housed and unhoused, and especially the underrepresentation of housed men in the sample, constrains our ability to consider the complex intersections between social class and gender, age, and level of identification with a place. Further research is needed to go beyond the role of housing status in conversations around safety and belonging in public spaces to explore the ways in which these dominant narratives may also be gendered and raced. In addition, future studies would benefit from a more in-depth exploration of the narratives constructed and performed by particular stakeholder groups, such as business owners, employees, local politicians, panhandlers, and street performers.

In addition, although our analysis was based on multiple data sources, the inclusion of only one local policy document limited our ability to draw inferences about existing cultural narratives. Future research directions might include examining multiple local policy documents in order to corroborate or expand on these findings. This study was also limited by its focus on a single community. Although the scope of this study is geographically limited, the ordinances and discourses employed to maintain (and resist) exclusion and inequality are not unique to Santa Cruz (see NLCHP 2014).

The findings of this study have implications for the creation of local public policies regarding the use of public spaces. Ordinances that target low income and unhoused people by prohibiting non-criminal activities such as sitting, sleeping, and standing may only serve to stigmatize the unhoused and exacerbate community tensions regarding economic development and inequality (see also Toolis and Hammack 2015). The United Nations Human Rights Committee (2014) recently condemned the US for allowing such laws, which promote "discrimination and cruel, inhuman, or degrading treatments" (p. 8). Consciousnessraising around the violation of safety and human rights posed by anti-homeless legislation might offer a response to economic inequality that facilitates the positive development of communities and the inclusion of all in a larger moral community. Recognition of the structural roots of poverty, including the lack of affordable housing and secure employment opportunities (Shinn et al. 2001), may represent the first step toward a more equitable and just community that is inclusive of and concerned with the welfare of all its members.

Acknowledgments The work presented here was supported by funding from the Psychology Department at the University of California, Santa Cruz. We wish to acknowledge the community members who graciously shared their time and stories with us and the field sites that supported our work. We thank Heather Bullock, Mary Beth Pudup, Miriam Greenberg, Andrew Pilecki, Anjali Dutt, Brandon Balzer-Carr, Harmony Reppond, Leifa Mayers, Robyn Goldberg,
Christine Brown, Rachel Beyer, Tajalei Willard, and Tamar Bezjian for their suggestions and contributions to this project. We also thank Jacob Tebes and an anonymous reviewer for their comments on earlier versions of this article.

\section{References}

Ammann, J. J. (2000). Addressing quality of life crimes in our cities: Criminalization, community courts and community compassion. St. Louis University Law Journal, 44(3), 811-820.

Amster, R. (2003). Patterns of exclusion: Sanitizing space, criminalizing homelessness. Social Justice, 30(1), 195-221.

Applied Survey Research. (2013). 2013 Santa Cruz County homeless point-in-time census \& survey: Comprehensive report. Retrieved from http://static1.squarespace.com/static/5176dcd7e4b0e5c0d ba41ee0/t/53ee6197e4b08be4e39a873b/1408131479031/Santa+ Cruz+Comprehensive+Report+-+2013.pdf.

Autor, D. (2011). The polarization of job opportunities in the U.S. labor market: Implications for employment and earnings. Community Investments, 23(2), 11-41.

Bakhtin, M. M. (1981). The dialogic imagination (C. Emerson \& M. Holquist, Trans.). Austin, TX: University of Texas Press.

Banerjee, T. (2001). The future of public space: Beyond invented streets and reinvented places. Journal of the American Planning Association, 67(1), 9-24.

Barnes, R. K. (2000). Losing ground: Locational formulations in argumentation over new travellers. Unpublished doctoral dissertation, Plymouth University; Plymouth, UK.

Barnes, R., Auburn, T., \& Lea, S. (2004). Citizenship in practice. British Journal of Social Psychology, 43(2), 187-206.

Braun, V., \& Clarke, V. (2006). Using thematic analysis in psychology. Qualitative Research in Psychology, 3(2), 77-101.

Bruner, J. S. (1990). Acts of meaning. Cambridge, MA: Harvard University Press.

Bullock, H. E. (2008). Justifying inequality: A social psychological analysis of beliefs about poverty and the poor. In A. C. Lin \& D. R. Harris (Eds.), The colors of poverty: Why racial and ethnic disparities persist (pp. 52-76). New York: Russell Sage Foundation.

Bullock, H. E. (2014). Social barriers to poverty reduction. In United Nations Development Programme, Barriers to and opportunities for poverty reduction: Prospects for private sector-led interventions (pp. 135-160). Retrieved from http://www.undp.org/ content/dam/istanbul/docs/2014_Barriers_to_and_Prospects_for_ Poverty_Reduction.pdf.

Bullock, H. E., \& Reppond, H. A. (in press). Of "takers" and "makers:" A social psychological analysis of class and classism. In P.L. Hammack (Ed.), Oxford handbook of social psychology and social justice. New York: Oxford University Press.

Case, A. D., \& Hunter, C. D. (2014). Counterspaces and the narrative identity work of offender-labeled African American youth. Journal of Community Psychology, 42(8), 907-923.

Case, A. D., Todd, N. R., \& Kral, M. J. (2014). Ethnography in community psychology: Promises and tensions. American Journal of Community Psychology, 54(1-2), 60-71.

City of Santa Cruz. (2013, December 3). City Council agenda: Study session. Retrieved from http://scsire.cityofsantacruz.com/sire $\mathrm{pub} / \mathrm{mtg}$ viewer.asp ? meetid=538\&doctype=AGENDA.

Code Publishing Company. (2014). Santa Cruz Municipal Code. Retrieved from http://www.codepublishing.com/ca/santacruz/.

Denzin, N. (1978). The research act: A theoretical introduction to sociological methods. New York: McGraw-Hill.

Di Masso, A. (2012). Grounding citizenship: Toward a political psychology of public space. Political Psychology, 33(1), 123-143. 
Dixon, J., \& Durrheim, K. (2000). Displacing place-identity: A discursive approach to locating self and other. British Journal of Social Psychology, 39(1), 27-44.

Dixon, J., \& Durrheim, K. (2004). Dislocating identity: Desegregation and the transformation of place. Journal of Environmental Psychology, 24(4), 455-473.

Dixon, J., Levine, M., \& McAuley, R. (2006). Locating impropriety: Street drinking, moral order, and the ideological dilemma of public space. Political Psychology, 27(2), 187-206.

Ferrell, J. (1997). Youth, crime, and cultural space. Social Justice, 24(4), 21-38.

Gaetz, S. (2004). Safe streets for whom? Homeless youth, social exclusion, and criminal victimization. Canadian Journal of Criminology and Criminal Justice, 46(4), 423-456.

Gendron, R., \& Domhoff, G. W. (2009). The leftmost city: Power and progressive politics in Santa Cruz. Boulder, CO: Westview.

Gergen, K. J. (1985). The social constructionist movement in modern psychology. American Psychologist, 40(3), 266-275.

Hammack, P. L. (2006). Identity, conflict, and coexistence: Life stories of Israeli and Palestinian adolescents. Journal of Adolescent Research, 21(4), 323-369.

Hammack, P. L. (2008). Narrative and the cultural psychology of identity. Personality and Social Psychology Review, 12(3), 222-247.

Hammack, P. L. (2010). The cultural psychology of Palestinian youth: A narrative approach. Culture \& Psychology, 16(4), 507-537.

Hammack, P. L. (2011). Narrative and the politics of meaning. Narrative Inquiry, 21(2), 311-318.

Hammack, P. L. (2014). Mind, story, society: The political psychology of narrative. In M. Hanne, W. Crano, \& J. S. Mio (Eds.), Warring with words: Narrative and metaphor in politics (pp. 51-77). New York: Psychology Press.

Hammack, P. L., \& Cohler, B. J. (2009). Narrative engagement and sexual identity: An interdisciplinary approach to the study of sexual lives. In P. L. Hammack \& B. J. Cohler (Eds.), The story of sexual identity: Narrative perspectives on the gay and lesbian life course (pp. 3-22). New York: Oxford University Press.

Hammack, P. L., \& Cohler, B. J. (2011). Narrative, identity, and the politics of exclusion: Social change and the gay and lesbian life course. Sexuality Research and Social Policy, 8, 162-182.

Hammack, P. L., \& Pilecki, A. (2012). Narrative as a root metaphor for political psychology. Political Psychology, 33(1), 75-103.

Hammack, P. L., \& Toolis, E. (2014). Narrative and the social construction of adulthood. New Directions in Child and Adolescent Development, 145, 43-56.

Harvey, D. (2008). The right to the city. New Left Review, 53, 23-40.

Hochschild, J. L. (1995). Facing up to the American dream: Race, class and the soul of the nation. Princeton, NJ: Princeton University Press.

Hodgetts, D., Stolte, O., Chamberlain, K., Radley, A., Nikora, L., Nabalarua, E., \& Groot, S. (2008). A trip to the library: Homelessness and social inclusion. Social and Cultural Geography, 9(8), 933-953.

Josselson, R. (2004). The hermeneutics of faith and the hermeneutics of suspicion. Narrative Inquiry, 14, 1-28.

Jost, J., \& Hunyady, O. (2003). The psychology of system justification and the palliative function of ideology. European Review of Social Psychology, 13(1), 111-153.

Krueger, A. (2012, January 12). The rise and consequence of inequality in the United States. Speech transcript retrieved from http://www.whitehouse.gov/sites/default/files/krueger_cap_speech_ final_remarks.pdf.

Laurenson, P., \& Collins, D. (2006). Towards inclusion: Local government, public space and homelessness in New Zealand. New Zealand Geographer, 62(3), 185-195.
Lefebvre, H. (1991). The production of space (Vol. 30). Oxford: Blackwell.

Lieblich, A., Tuval-Mashiach, R., \& Zilber, T. (1998). Narrative research: Reading, analysis, and interpretation. Thousand Oaks, CA: Sage.

Limbert, W. M., \& Bullock, H. E. (2009). Framing US redistributive policies: Tough love for poor women and tax cuts for seniors. Analyses of Social Issues and Public Policy, 9(1), 57-83.

Lott, B. (2002). Cognitive and behavioral distancing from the poor. American Psychologist, 57(2), 100-110.

Lott, B., \& Bullock, H. E. (2007). Psychology and economic injustice: Personal, professional, and political intersections. Washington, DC: American Psychological Association Press.

Mathison, S. (1988). Why triangulate? Educational Researcher, 17(2), 13-17.

Mitchell, D. (1995). The end of public space? People's Park, definitions of the public, and democracy. Annals of the Association of American Geographers, 85(1), 108-133.

Mitchell, D. (1997). The annihilation of space by law: The roots and implications of anti-homeless laws in the United States. Antipode, 29(3), 303-335.

National Coalition for the Homeless (NHC). (2014, June). Vulnerable to hate: A survey of hate crimes \& violence committed against the homeless in 2013. Retrieved from http://nationalhomeless. org/wp-content/uploads/2014/06/Hate-Crimes-2013-1.pdf.

National Law Center on Homelessness \& Poverty (NLCHP). (2014). No safe place: The criminalization of homelessness in U.S. cities. Retrieved from http://www.nlchp.org/documents/No_Safe_Place.

National Low Income Housing Coalition (NLIHC). (2014). Out of reach 2014: Twenty-five years later, the affordable housing crisis continues (pp. 1-241). Retrieved from http://nlihc.org/oor/ 2014.

Onishi, N. (2013, March 24). Violence brings an identity crisis in a free-spirited California beach town. The New York Times. Retrieved from http://www.nytimes.com/2013/03/25/us/vio lence-spurs-identity-crisis-in-free-spirited-santa-cruz.html?page wanted $=1 \& \_r=1$.

Opotow, S. (1990). Moral exclusion and injustice: An introduction. Journal of Social Issues, 46(1), 1-20.

Opotow, S. (2006). Seeking inclusion and pluralism: Two exploratory studies. Peace and Conflict: Journal of Peace Psychology, 12(4), 349-366.

Opsal, T. D. (2011). Women disrupting a marginalized identity: Subverting the parolee identity through narrative. Journal of Contemporary Ethnography, 40(2), 135-167.

Pascale, C. M., \& West, C. (1997). Social illusions: Responses to homelessness in Santa Cruz, California, 1989-1994. Perspectives on Social Problems, 9, 3-29.

Public Safety Citizen Task Force. (2013, December). Research, findings and recommendations: Santa Cruz City Public Safety Citizen Task Force (pp. 1-47). Retrieved from http://www. cityofsantacruz.com/home/showdocument?id=35125.

Ramirez, L. C., \& Hammack, P. L. (2014). Surviving colonization and the quest for healing: Narrative and resilience among California Indian tribal leaders. Transcultural Psychiatry, 51(1), 112-133.

Rappaport, J. (2000). Community narratives: Tales of terror and joy. American Journal of Community Psychology, 28(1), 1-24.

Reich, R. B. (2010). Aftershock: The next economy and America's future. New York: Knopf Doubleday.

Runyan, W. M. (1980). The Life Satisfaction Chart: Perceptions of the course of subjective experience. International Journal of Aging and Human Development, 11(1), 45-64.

Shinn, M., Baumohl, J., \& Hopper, K. (2001). The prevention of homelessness revisited. Analyses of Social Issues and Public Policy, 1(1), 95-127. 
Sleeper, A. (2014, January 14). Out in the cold. Good times. Retrieved from http://www.gtweekly.com/index.php/santa-cruz-news/ santa-cruz-environmental-news/5336-out-in-the-cold.html.

Snow, D. A., Baker, S. G., \& Anderson, L. (1989). Criminality and homeless men: An empirical assessment. Social Problems, 36(5), 532-549.

Snow, D. A., \& Mulcahy, M. (2001). Space, politics, and the survival strategies of the homeless. American Behavioral Scientist, 45(1), 149-169.

Sonn, C. C., \& Fisher, A. T. (1998). Sense of community: Community resilient responses to oppression and change. Journal of Community Psychology, 26(5), 457-472.

Stiglitz, J. E. (2012). The price of inequality: How today's divided society endangers our future. New York: W. W. Norton.

Substance Abuse and Mental Health Services Administration (SAMHSA). (2011, July). Current statistics on the prevalence and characteristics of people experiencing homelessness in the United States. Retrieved from http://homeless.samhsa.gov/ ResourceFiles/hrc_factsheet.pdf.

Susser, I. (1996). The construction of poverty and homelessness in US cities. Annual Review of Anthropology, 25, 411-435.

Tappan, M. B. (1997). Interpretive psychology: Stories, circles, and understanding lived experience. Journal of Social Issues, 53(4), 645-656.

Tileagă, C. (2006). Representing the "other": A discursive analysis of prejudice and moral exclusion in talk about Romanies. Journal of Community \& Applied Social Psychology, 16(1), 19-41.

Tileagă, C. (2007). Ideologies of moral exclusion: A critical discursive reframing of depersonalization, delegitimization and dehumanization. British Journal of Social Psychology, 46(4), 717-737.
Toolis, E. E., \& Hammack, P. L. (2015). The lived experience of homeless youth: A narrative approach. Qualitative Psychology, 2(1), 50.

United Nations Human Rights Committee. (2014, April 23). International covenant on civil and political rights: Concluding observations on the fourth periodic report of the United States of America (p. 8). Retrieved from http://www.refworld.org/docid/ 5374afcd4.html.

U.S. Department of Housing and Urban Development (HUD). (2013). The 2013 annual homeless assessment report (AHAR) to Congress: Point-in-time estimates of homelessness (pp. 1-58). Retrieved from https://www.hudexchange.info/resources/docu ments/ahar-2013-part1.pdf.

U.S. Interagency Council on Homelessness. (2013). Opening doors: Chronic homelessness. Retrieved from http://usich.gov/usich_ resources/fact_sheets/opening_doors_chronic_homelessness/.

Western Regional Advocacy Project. (2014, September 8). National civil rights outreach fact sheet. Retrieved from http://wraphome. org/images/stories/hbr/NationalCivilRightsFactSheetDecember 2014.pdf.

White, R. (1993). Youth and the conflict over urban space. Children's Environments, 10(1), 85-93.

Wright, T. (1997). Out of place: Homeless mobilizations, subcities, and contested landscapes. Albany, NY: State University of New York Press.

Wright, T. (2000). Resisting homelessness: Global, national, and local solutions. Contemporary Sociology, 29(1), 27-43. 